\title{
Prevalence of the carbapenemase gene (cfiA) among clinical and normal flora isolates of Bacteroides species in Hungary
}

\author{
J. SÓKI, E. URBAN, I. SZÖKE, E. FODOR and E. NAGY \\ Department of Clinical Microbiology, Albert Szent-Györgyi Medical University, Szeged, Hungary
}

\begin{abstract}
The carbapenemase gene (cfiA) was detected in 4 (5.7\%) of 70 clinical isolates of Bacteroides fragilis from different parts of Hungary. Among 24 other Bacteroides species isolated from infectious processes or from normal faecal flora, none was $c f i A$-positive. The MIC of imipenem and meropenem for all cfiA-positive $B$. fragilis isolates was $\leqslant 0.25 \mathrm{mg} / \mathrm{L}$, but $17 \%$ of the $B$. fragilis and $46 \%$ of the non-fragilis Bacteroides isolates exhibited reduced susceptibility to imipenem (MICs $0.5-2 \mathrm{mg} / \mathrm{L}$ ). Only one of these isolates produced increased levels of $\beta$-lactamase. No difference was observed in the outer-membrane proteins of $B$. fragilis isolates that harboured the $c f i A$ gene and those with reduced susceptibility to imipenem.
\end{abstract}

\section{Introduction}

Members of the genus Bacteroides (B. fragilis group) are frequently isolated from infections after abdominal or gynaecological surgery [1]. These infections are usually polymicrobial and demand the use of potent antibiotics, covering both aerobic and anaerobic pathogens. Increasing resistance of anaerobic bacteria to the antimicrobial agents used for the treatment of anaerobic infections, and differences in the rates of resistance between various hospitals and countries have been reported $[2,3]$. Resistance to $\beta$-lactam antibiotics in anaerobic bacteria involves the production of $\beta$ lactamases, alterations in the penicillin-binding proteins, or the reduced penetration of the antibiotics through the bacterial outer membrane [4]. In Bacteroides spp., resistance to $\beta$-lactam agents is most often mediated by chromosomal class A $\beta$-lactamases with predominant cephalosporinase activity, which are virtually ubiquitous in B. fragilis group isolates [5], although the amount of the enzyme varies greatly from isolate to isolate. These enzymes are inhibited by clavulanate, tazobactam and sulbactam and do not hydrolyse cephamycins or carbapenems. Several studies [6-9] have suggested that $0.7-3 \%$ of $B$. fragilis strains produce class $\mathrm{B}$ carbapenem-hydrolysing metallo- $\beta$ lactamases, which are inhibited by ethylenediaminetetraacetic acid (EDTA), but not by the clinically used $\beta$ -

Received 14 Sept. 1999; revised version received 28 Oct. 1999; accepted 12 Nov. 1999.

Corresponding author: Dr E. Nagy (e-mail: NAGYE@, mlab.szote.U-Szeged.Hu). lactamase inhibitors. The $c f i A$ gene coding this enzyme has been cloned and sequenced. It may be 'silent' or expressed to various degrees, resulting in a wide range of levels of carbapenem resistance. Some strains harbouring the cfiA gene appear sensitive to carbapenems on conventional testing, but can convert to highlevel resistance following antibiotic pressure [8]. Clinically relevant $B$. fragilis strains, with or without the presence of the $c f i A$ gene, have been reported from different countries to be resistant to imipenem (MIC $\geqslant 16 \mathrm{mg} / \mathrm{L}$ ), or to display only a decreased susceptibility (MIC $\geqslant 1 \mathrm{mg} / \mathrm{L})[9,10]$. The present study looked for the presence of the cfiA gene by the PCR in clinical isolates of $B$. fragilis collected at three different centres in Hungary. A limited number of strains belonging to other species of Bacteroides, obtained from clinical samples or from the normal faecal flora, were also tested.

\section{Materials and methods}

\section{Bacterial strains and plasmid}

Seventy randomly selected, clinically significant $B$. fragilis isolates and 24 isolates of other Bacteroides species (including 10 isolates obtained from faeces of healthy subjects) were collected during 1998 from a large university hospital in south-east Hungary (39 isolates), a large community hospital in the central part of the country ( 21 isolates) and a small hospital in western Hungary (10 isolates). Isolates were identified by conventional tests or by the Rapid ID 32A system (bioMérieux). B. fragilis NCTC 9344 (carbapenem- 
sensitive) and $B$. fragilis TAL3636 (a metallo- $\beta$ lactamase producer), kindly provided by R. Edwards (Nottingham University), were included as controls. The pJST241 plasmid, carrying the cloned c fiA gene [8], was obtained from M. H. Malamy (Boston, MA, USA). The Qiagen Mini Plasmid Purification kit (Qiagen, Hilden, Germany) was used for plasmid isolation.

\section{Antibiotic resistance determination}

MICs of carbapenems were determined by the Etest (AB Biodisk, Stockholm, Sweden) on brain heart infusion (BHI) agar supplemented with yeast extract $5 \mathrm{~g} / \mathrm{L}$, haemin $5 \mathrm{mg} / \mathrm{L}$ and menadione $1 \mathrm{mg} / \mathrm{L}$ according to the manufacturer's instructions. MICs were read after incubation for $48 \mathrm{~h}$ in an anaerobic environment (Bactron, Shell Lab., Cornelius, USA).

\section{Determination of $\beta$-lactamase activity}

$\beta$-Lactamase activity was determined quantitatively with $(0.10 \mathrm{mM})$ nitrocefin in $50 \mathrm{mM}$ sodium phosphate buffer $\left(\mathrm{pH} 7.0,37^{\circ} \mathrm{C}\right)$ by a spectrophotometric method [11]. One unit of $\beta$-lactamase was defined as the amount that formed $1.0 \mu$ mole of product $/ \mathrm{min}$ under the given conditions.

\section{Investigation of outer-membrane proteins}

Outer-membrane proteins (OMPs) of selected $B$. fragilis isolates (four strains that were cfiA-positive, but imipenem susceptible and four that were cfiAnegative, but for which the MIC of imipenem was 1$2 \mathrm{mg} / \mathrm{L}$ ) were examined by a method based on that described by Carlone et al. [12]. The OMPs were solubilised by boiling with $50 \mu \mathrm{l}$ of Laemmli sample buffer for $5 \mathrm{~min}$ and separated by SDS-PAGE.

\section{Detection of the cfiA gene by PCR}

Bacterial cells from the surface of BHI agar plates were suspended in water and boiled for $10 \mathrm{~min}$. The supernates of the centrifuged suspensions ( $2 \mathrm{~min}$ at $10000 \mathrm{rpm}$ ) were used as template DNA. Reaction mixtures each contained $5 \mu \mathrm{l}$ of 10 -fold concentrated reaction buffer (Sigma or USB), $1 \mu 1(2.5 \mathrm{mM})$ each of dATP, dCTP, dGTP and dTTP (Sigma), $1 \mu \mathrm{l}$ (35 pmoles) of each primer, $5 \mu \mathrm{l}$ of template DNA, $33 \mu \mathrm{l}$ of sterile water and $1 \mathrm{U}$ of Taq polymerase (Sigma). The primers had the nucleotide 557-582 sequence 5'-TCC ATG CTT TTC CCT GTC GCA GTT AT-3' and the complementary 1266-1285 sequence 5'-GGG CTA TGG CTT TGA AGT GC-3' [8]. The reaction mixtures were incubated for 40 cycles in a programmable heating block (GeneAmp, PCR System 9600, Perkin Elmer, Norwalk, CT, USA) for $1 \mathrm{~min}$ at $92^{\circ} \mathrm{C}, 2 \mathrm{~min}$ at $50^{\circ} \mathrm{C}$ and $2 \mathrm{~min}$ at $72^{\circ} \mathrm{C}$ with a final extension of $10 \mathrm{~min}$. PCR products were visualised on agarose gels containing ethidium bromide under UV light and their sizes were compared with those of a mol. wt marker (100-bp DNA ladder, Sigma) and the product generated from B. fragilis TAL3636 as a positive control.

Southern blotting with a cfiA-specific probe obtained from the PCR product of the pJST241 plasmid was used to confirm the PCR results. PCR products were resolved on agarose $1 \%$ gels and transferred to nylon membranes (Amersham, UK) by capillary transfer. Radioactive labelling of the probe was performed with the Megaprime random priming kit (Amersham) under the conditions recommended by the supplier. Prehybridisation at $65^{\circ} \mathrm{C}$ for $1 \mathrm{~h}$ was followed by hybridisation at $65^{\circ} \mathrm{C}$ overnight in $5 \times$ concentrated saline sodium citrate (SSC) buffer and $5 \times$ concentrated Denhardt's solution containing sodium dodecyl sulphate (SDS) $0.5 \% \mathrm{w} / \mathrm{v}$ and salmon sperm DNA $100 \mu \mathrm{g} / \mathrm{ml}$. Radioactively labelled probe DNA with an activity of $c$. $10^{7} \mathrm{cpm}$ was added to the hybridisation solution after pre-hybridisation. The filters were washed twice in double-strength SSC and SDS $0.1 \% \mathrm{w} / \mathrm{v}$ at $65^{\circ} \mathrm{C}$ for $15 \mathrm{~min}$, and twice in $0.2 \times \mathrm{SSC}$ and SDS $0.1 \% \mathrm{w} / \mathrm{v}$ at $65^{\circ} \mathrm{C}$ for $15 \mathrm{~min}$. Damp filters were packed in Saran Wrap and were exposed to X-ray films at $-70^{\circ} \mathrm{C}$ with an intensifying screen.

\section{Nucleotide sequencing}

Before nucleotide sequencing, the amplified PCR sample was precipitated with three volumes of $7.5 \mathrm{M}$ ammonium acetate and absolute ethanol (1:5 v:v) at room temperature to remove unincorporated primers. DNA sequencing was performed with an automated sequencer (ABPrism model 373, Applied Biosystems) with an AmpliTaq FS DyeDeoxy terminator cycle sequencing kit (Applied Biosystems). The DNA sequence obtained was compared with those of known carbapenemase genes from Bacteroides spp. with the BLAST client programme accessible from the Internet at the National Center for Biotechnology Information.

\section{Results and discussion}

The MICs of imipenem for $70 \mathrm{~B}$. fragilis and 24 nonfragilis isolates ranged from $\leqslant 0.06$ to $2 \mathrm{mg} / \mathrm{L}$. No resistant strain was observed according to the NCCLS breakpoint criterion (MIC $\geqslant 16 \mathrm{mg} / \mathrm{L}$ ) [13]. However, $12 \mathrm{~B}$. fragilis isolates $(17 \%)$ and 11 non-fragilis isolates $(46 \%)$ exhibited reduced susceptibility to imipenem (MICs $0.5-2 \mathrm{mg} / \mathrm{L}$ ). The cfiA gene was detected in four $B$. fragilis isolates and in none of the non-fragilis isolates by PCR. Southern blotting of the PCR products revealed homology to the pJST241 probe in B. fragilis isolates 20,72 and 98. The PCR product of $B$. fragilis isolate 22 did not hybridise, but sequence analysis of the product showed that it bore c. $96 \%$ homology to known cfiA genes, indicating that it represents a carbapenemase gene fragment. 
Table 1. MICs of carbapenems and the presence of the cfiA gene in selected $B$. fragilis isolates obtained from clinical specimens

\begin{tabular}{|c|c|c|c|c|}
\hline \multirow[b]{2}{*}{ Isolate } & \multicolumn{2}{|c|}{$\mathrm{MIC}(\mathrm{mg} / \mathrm{L})$ of } & \multirow[b]{2}{*}{$c f i A$} & \multirow{2}{*}{$\begin{array}{c}\beta \text {-lactamase } \\
\text { activity } \\
(\mathrm{U} / \mathrm{min})\end{array}$} \\
\hline & imipenem & meropenem & & \\
\hline B. fragilis 22 & 0.06 & 0.125 & + & 0.0175 \\
\hline B. fragilis 20 & 0.06 & 0.06 & + & 0.0028 \\
\hline B. fragilis 98 & 0.125 & 0.25 & + & 0.0004 \\
\hline B. fragilis 72 & 0.25 & 0.25 & + & 0.0109 \\
\hline B. fragilis 91 & 1.0 & 0.5 & - & 0.0140 \\
\hline B. fragilis 76 & 1.0 & 0.125 & - & 0.0087 \\
\hline B. fragilis 68 & 2.0 & 1.0 & - & 2.9540 \\
\hline B. fragilis 54 & 2.0 & 2.0 & - & ND \\
\hline B. vulgatus 38 & 1.0 & 1.0 & - & 0.0152 \\
\hline B. thetaiotaomicron 55 & 2.0 & 2.0 & - & 0.0185 \\
\hline B. ovatus 42 & 2.0 & 2.0 & - & ND \\
\hline
\end{tabular}

The MICs of imipenem and meropenem for the four cfiA-positive isolates were $0.06-0.25 \mathrm{mg} / \mathrm{L}$ (Table 1). Very low $\beta$-lactamase activities were measured in these isolates. $\beta$-Lactamase activities were also low for three $B$. fragilis and three Bacteroides non-fragilis isolates, for which the MIC of imipenem was 1 or $2 \mathrm{mg} / \mathrm{L}$. One strain (B. fragilis 68), for which the MICs of imipenem and meropenem were 1 and $2 \mathrm{mg} / \mathrm{L}$, respectively, was found to have high $\beta$-lactamase activity. PAGE analysis of the OMPs of the B. fragilis isolates with elevated MICs and those that were fully susceptible, but harboured the $c f i A$ gene, revealed no difference (results not shown). Similar results have been described by Edwards and Greenwood [14].

No imipenem-resistant isolate has yet been reported in Hungary (the MIC90 was $0.5 \mathrm{mg} / \mathrm{L}$ in 1992 and $1 \mathrm{mg} / \mathrm{L}$ in 1992-1993), despite the fact that imipenem or meropenem are increasingly used for treatment of severe infections involving aerobic and anaerobic bacteria $[10,15]$. Low rates of resistance to imipenem among $B$. fragilis strains have been found in France [2] and in the USA [16], whereas in Japan, where imipenem is widely used, 2.4, 4.5 and $10.5 \%$, respectively, of the $B$. fragilis, $B$. thetaiotaomicron and $B$. distasonis isolates tested were resistant to imipenem [17]. However, the resistance breakpoint used in the Japanese study $(6.25 \mathrm{mg} / \mathrm{L})$ was lower than that recommended by NCCLS guidelines $(16 \mathrm{mg} / \mathrm{L})$. High-level resistance to imipenem was also found to be rare among $B$. fragilis isolates collected in Nottingham, UK [9], although $12 \%$ of 175 Bacteroides isolates from clinical specimens exhibited a reduced susceptibility to imipenem (MICs $0.5-2 \mathrm{mg} / \mathrm{L}$, i.e., concentrations up to 50 times higher than those for 'normal' sensitive strains [9]). In the present study, MICs of imipenem for $17 \%$ of the $B$. fragilis and $46 \%$ of the non-fragilis isolates were $\geqslant 10$-fold higher than those for fully sensitive strains. The percentage of clinical isolates of B. fragilis $(5.7 \%)$ found to possess the $c f i A$ gene in the present study is substantially more than the rate reported from France (2.4\%) [6], but similar to that observed by Edwards et al. [9].
All four cfiA-positive strains were obtained from patients in a large university hospital. Although these isolates would be classified as sensitive by conventional breakpoint criteria, they have the potential to convert to a high level of metallo- $\beta$-lactamase expression by acquisition of an insertion element carrying an efficient promoter of the $c f i A$ gene [18].

Few clinically relevant Bacteroides strains have been reported world-wide to harbour the cfiA gene or to express metallo- $\beta$-lactamase production, resulting in carbapenem resistance and possible failure of therapy. However, Fang et al. [19] found the cfiA gene in faecal isolates of $B$. fragilis and species other than $B$. fragilis with high-level production of metallo- $\beta$-lactamase have also been isolated [20]. Careful monitoring of changes in the imipenem resistance of Bacteroides strains isolated from clinical samples and from normal faecal flora, together with screening for the cfiA gene, are important to follow the emergence and spread of carbapenem resistance in different parts of the world.

This work was supported by grant T016222 from the Hungarian National Research Foundation (OTKA). We thank L. Szikra for collecting clinical isolates for this study. We are also grateful to R. Edwards, Nottingham and M. H. Malamy, Boston for providing $B$. fragilis strains NCTC9344 and TAL3636 and the pJST241 plasmid, respectively.

\section{References}

1. Finegold SM, Lance GW. Anaerobic infections in humans. San Diego, Academic Press. 1989.

2. Dubreuil L, Derriennic M, Sedallian A, Romond C, Courtieu AL. Evaluation of antibiotic susceptibility of Bacteroides fragilis group strains in France based on periodic surveys. Infection 1989; 17: 197-200.

3. Phillips I, King A, Nord CE, Hoffstedt B. Antibiotic sensitivity of the Bacteroides fragilis group in Europe. European Study Group. Eur J Clin Microbiol Infect Dis 1992; 11: 292-304.

4. Nord CE, Hedberg M. Resistance to beta-lactam antibiotics in anaerobic bacteria. Rev Infect Dis 1990; 12 Suppl 2: S231S234.

5. Livermore DM. Beta-lactamases in laboratory and clinical resistance. Clin Microbiol Rev 1995; 8: 557-584.

6. Podglajen I, Breuil J, Casin I, Collatz E. Genotypic identification of two groups within the species Bacteroides fragilis by ribotyping and by analysis of PCR-generated fragment patterns 
and insertion sequence content. J Bacteriol 1995; 177: 52705275 .

7. Edwards R, Thirlwell D, Greenwood D. Changes in beta-lactam antibiotic susceptibility and beta-lactamase production of clinical isolates of Bacteroides and Prevotella species over a 9 year period. J Antimicrob Chemother 1996; 37: 636-638.

8. Podglajen I, Breuil J, Bordon F, Gutmann L, Collatz E. A silent carbapenemase gene in strains of Bacteroides fragilis can be expressed after a one-step mutation. FEMS Microbiol Lett 1992; 91: 21-30.

9. Edwards R, Hawkyard CJ, Garvey MT, Greenwood D. Prevalence and degree of expression of the carbapenemase gene (cfiA) among clinical isolates of Bacteroides fragilis in Nottingham, UK. J Antimicrob Chemother 1999; 43: 273-276.

10. Nagy E, Szöke I, Gacs M, Csiszár K. Antibiotic susceptibility of Bacteroides fragilis group strains in Hungary. Anaerobe 1995; 1: 269-274.

11. Kesado T, Lindqvist L, Hedberg M, Tunér $K$, Nord CE. Purification and characterization of a new beta-lactamase from Clostridium butyricum. Antimicrob Agents Chemother 1989; 33: $1302-1307$

12. Carlone GM, Thomas ML, Rumschlag HS, Sottnek FO. Rapid microprocedure for isolating detergent-insoluble outer membrane proteins from Haemophilus species. J Clin Microbiol 1986; 24: 330-332.

13. National Committee for Clinical Laboratory Standards. Interpretative categories and correlative minimum inhibitory concentrations (MICs), 4th edn. Document M11-A4. NCCLS. 1997.
14. Edwards R, Greenwood D. Outer membrane analysis of $B$. fragilis strains with reduced susceptibility to imipenem. In: Duerden BI, Wade WG, Brazier JS, Eley A, Wren B, Hudson MJ (eds) Medical and dental aspects of anaerobes. Northwood, Middlesex, Science Reviews. 1995: 307-309.

15. Nagy E, Szöke I, Gacs M, Csiszár K. Resistance to betalactam antibiotics and beta-lactamase production of Bacteroides, Porphyromonas and Prevotella strains. Acta Microbiol Immunol Hung 1995; 42: 287-299.

16. Wexler HM, Finegold SM. In vitro activity of cefoperazone plus sulbactam compared with that of other antimicrobial agents against anaerobic bacteria. Antimicrob Agents Chemother 1988; 32: 403-406.

17. Bandoh K, Ueno K, Watanabe K, Kato N. Susceptibility patterns and resistance to imipenem in the Bacteroides fragilis group species in Japan: a 4-year study. Clin Infect Dis 1993; 16 Suppl 4: S382-S386.

18. Podglajen I, Breuil J, Collatz E. Insertion of a novel DNA sequence, IS1186, upstream of the silent carbapenemase gene cfiA, promotes expression of carbapenem resistance in clinical isolates of Bacteroides fragilis. Mol Microbiol 1994; 12: 105114.

19. Fang H, Edlund C, Hedberg M. Detection of imipenem resistant and metronidazole resistant Bacteroides fragilis group strains in faecal samples. Clin Microbiol Infect (in press).

20. Podglajen I, Breuil J, Rybkine T, Collatz E. Emergence of cfiA-mediated carbapenem resistance in Bacteroides distasonis. Program and Abstracts of the 38th ICCAC. Washington, DC, ASM Press. 1998: 118. 